\title{
RHIZOPHAGUS INTRARADICES AND TOMATO-BASIL COMPANIONSHIP AFFECT ROOT MORPHOLOGY AND ROOT EXUDATE DYNAMICS IN TOMATO UNDER FUSARIUM WILT DISEASE STRESS
}

\author{
RAZA, S. M. J. ${ }^{1}-$ AKHTER, A. ${ }^{1 *}-$ WAHID, F. $^{2}$ - HASHEM, A. ${ }^{3,4}-$ ABD_Allah, E. F. ${ }^{5}$ \\ ${ }^{I}$ Department of Plant Pathology, Faculty of Agricultural Sciences, University of the Punjab, \\ Quaid-i-Azam Campus, PO Box 54590, Lahore, Pakistan \\ ${ }^{2}$ Department of Agriculture, University of Swabi, Khyber Pakhtunkhwa, Pakistan \\ ${ }^{3}$ Botany and Microbiology Department, College of Science, King Saud University, PO Box \\ 2460, Riyadh 11451, Saudi Arabia \\ ${ }^{4}$ Mycology and Plant Disease Survey Department, Plant Pathology Research Institute, ARC, \\ Giza 12511, Egypt \\ ${ }^{5}$ Plant Production Department, College of Food and Agricultural Sciences, King Saud \\ University, PO Box 2460, Riyadh 11451, Saudi Arabia \\ *Corresponding author \\ e-mail: adnanakhter.iags@pu.edu.pk; phone: +92-322-602-3186; fax: +92-429-923-1846
}

(Received $18^{\text {th }}$ Jul 2021; accepted $1^{\text {st }}$ Oct 2021)

\begin{abstract}
Combining the benefits of intercropping with arbuscular mycorrhizal fungi (AMF) can be an additional tool for managing the soil-borne diseases in sustainable land management systems. The present study was designed to investigate the influence of basil (Ocimum basilicum L.) as an intercropping partner and arbuscular mycorrhizal fungi (Rhizophagus intraradices: AMF) on tomato (Solanum lycopersicum L.) root morphology and exudation both in the presence and absence of Fusarium wilt (Fusarium oxysporum f. sp. lycopersici, FOL) disease stress. Experiments were conducted in a root compartment system. Our results indicated that intercropping tomato with basil did not only increase the plant biomass but also significantly reduced disease severity in tomatoes. Moreover, tomato plants intercropped with basil and co-inoculated with AMF and FOL had higher root lengths, volume and surface areas as compared to the plants in tomato-tomato combination. In vitro studies of FOL microconidia germination in tomato root exudates revealed significantly lower germination rate in the root exudates of AMF colonized tomatoes intercropped with basil than in exudates of tomato intercropped with tomato. In conclusion, intercropping basil with tomato successfully alleviates Fusarium wilt stress even without direct root contact. The addition of AMF increases the tolerance of the host plant towards Fusarium wilt by affecting tomato root morphology and exudation dynamics.
\end{abstract}

Keywords: interspecific communication, soil fungi, intercropping, arbuscular mycorrhiza, biological control

\section{Introduction}

Fusarium wilt is a potent devastating factor for tomato (Solanum lycopersicum L.) cultivation all over the world. The wilting of tomato caused by a soil borne fungus Fusarium oxysporum f. sp. lycopersici (FOL) is responsible for massive crop losses all over the world. Yield losses due to Fusarium wilt vary between tomato cultivation systems and may reach up to $45 \%$, as recently reported in India (Ramyabharathi et al., 2012). As a result, sound and effective disease management strategies are needed to ensure maximum tomato production and protection without harming the environment.

Intercropping or co-cultivation of two crops together has been utilized as a mean of subsistence farming in Asia, Latin and North America, Europe and Africa. It is being 
largely practiced to promote organic gardening, increasing land use efficiency and as a part of integrated pest management strategies (Bomford, 2009). The emphasis of farmers and environmentalists on the chemical free approaches to control diseases by utilizing companion crops with stimulating and suppressing effects on plant growth and disease development, respectively, is growing as well (Fu et al., 2015). Intercropping different plant species has been proposed to offer benefits including increase in yield, protection from pest and diseases (Son et al., 2018); however, the scientific backing of these proposed benefits is lacking due to the small number of studies in this regard.

The selection of a proper cropping partner is very important to avoid negative effects on the main crop. Basil (Ocimum basilicum L.) is an aromatic herb, when intercropped with tomato is suggested to improve tomato growth, yield and flavor, whereas other members of the family Brassicaceae, for instance Brussels sprout (Brassica oleracea L.) and tomato are antagonistic to each other (Riotte, 1975; Bomford, 2009). Salehi et al. (2018) reported an increase in water use efficiency of tomatoes growing with basil in the intercrop setting. Rice (1984) has termed the phenomenal influence of intercrops on each other by plant secondary metabolites or through the by-products of main metabolic pathways as allelopathy. There are also reports concerning allelochemicals acting as natural pesticides against fungal and bacterial pathogens (Farooq et al., 2011). For example, two allelochemicals 5,7,40-trihydroxy-30,50-dimethoxyflavone and 3isopropyl-5-acetoxycyclohexene-2-one-1 has been isolated from rice, which inhibited the germination of spores of two fungal pathogens Rhizoctonia solani and Pyricularia oryzae (Kong et al., 2004). However, the knowledge is limited about the consequences of companion crops such as basil on the main crop tomato in terms of protection against FOL.

Arbuscular mycorrhizal fungi (AMF) form a symbiosis with approximately $80 \%$ of all land plants and thereby exhibit positive effects on their host plant (Brundrett, 2002; Smith and Read, 2008). The mycorrhizal association with tomato plant roots modifies root morphology, facilitates absorption of nutrients and most importantly induces systemic resistance against Fusarium oxysporum f. sp. lycopersici (Dehne and Schönbeck, 1979; Scheffknecht et al., 2006). Combining the positive effects of the proper intercropping partner with the application of AMF might be a promising additional tool in sustainable disease management strategies. Increased Fusarium wilt suppression in tomato using basil as intercropping partner has already been demonstrated (Hage-Ahmed et al., 2013a). However, root morphological traits and root exudation dynamics in the tomato-basil intercropping setting and their putative contribution to less diseased plants remain to be elucidated. Thus, in this work a root compartment system separated by a fine mesh $(\varnothing 60 \mu \mathrm{m})$ allowing AM hyphae to pass was used to evaluate root morphological traits and their contribution to Fusarium wilt suppression in the tomato-basil intercropping setting.

\section{Materials and methods}

\section{Plant material}

Tomato (Solanum lycopersicum L. cv. Roma) and basil (Ocimum basilicum L. cv. Genovese) seeds were surface sterilized by soaking in 50\% commercial bleach $(3.5 \%$ $\mathrm{NaOCl}$ ) for $10 \mathrm{~min}$, followed by rinsing with sterilized distilled water thrice. Afterwards, seeds were sown in a tray containing sterilized sandy loam soil having clay, silt and sand $(18-23 \%, 52-57 \%$ and $23-25 \%$, respectively). The trays were covered with polythene bags 
to maintain humidity for optimum germination at $24{ }^{\circ} \mathrm{C}$. Tap water was used for irrigating the pots. The seedlings were grown for four weeks before transplanting.

\section{Fungal culture}

Fusarium oxysporum f. sp. lycopersici isolate was provided by the First fungal culture bank of Pakistan, University of the Punjab Lahore, Pakistan. The fungus was cultivated at $24{ }^{\circ} \mathrm{C}$ for 15 days on Potato dextrose Agar medium (Merck KGaA, Darmstadt, Germany) in the dark. Microconidia suspension of FOL was prepared by flooding the culture plates with sterilized distilled water and rubbing the mycelium with spatula. The suspension was filtered through three layers of filter paper (filters, $150 \mu \mathrm{m}$ pore diameter). For plant inoculation, the final concentration was adjusted to $1 \times 10^{5}$ microconidia $\mathrm{ml}^{-1}$ by using a haemocytometer. For AMF inoculation, a commercially available inoculum containing Rhizophagus intraradices (Xtreme Gardening, HGC721205 Mykos Pure Mycorrhizal Inoculant) was used.

\section{Experimental design}

Pre-cultivated seedlings of tomato and basil were transferred to a modified compartment system (rhizobox) adopted from Vierheilig et al. (2000). Each rhizobox made up of wooden material and comprised of two compartments separated by a nylon membrane of $60 \mu \mathrm{m}$ mesh size fixed on a dissector. The membrane can be passed by AM hyphae but excludes the roots. So, each box had two sub-compartments allowing only one intercropping combinations per rhizobox. The rhizoboxes were filled with an autoclaved mixture of sand, and soil at the ratio of 1:1 ( v/v). The experimental setup consisted of two plant combinations (tomato-tomato and tomato-basil), along with the inoculation of plants with $R$. intraradices and $F$. oxysporum $\mathrm{f}$. sp. lycopersici. The treatment plan was as followed: 1) tomato-tomato combination (TT), 2) tomato-tomato with AMF (TTM), 3) tomato-basil (TB) and 4) tomato-basil with AMF (TBM). The treatments were either inoculated with $F$. oxysporum $\mathrm{f}$. sp. lycopersici $(+\mathrm{Fol})$ or uninoculated (-Fol). The experiment was done in a random design with six replicates in two repeats for each treatment. The experiment was conducted at the greenhouse facility of Faculty of Agricultural Sciences, University of the Punjab (Lahore, Pakistan).

For the AMF inoculation, $4 \mathrm{ml}$ of the inoculum was mixed with the soil around the planting hole before seedling transplantation. In case of $F$. oxysporum $\mathrm{f}$. sp. lycopersici inoculation, only tomato plants were inoculated by dipping the slightly clipped roots in conidial suspension $\left(1 \times 10^{5}\right.$ microconidia $\left.\mathrm{ml}^{-1}\right)$ for 5 min before transplanting, whereas in case of AMF inoculation, both tomato and basil transplants received the inoculum. The rhizoboxes with the plantlets were placed in the greenhouse for 6 weeks. The plants were irrigated with water according to the moisture requirements and fertilized once a week with a nutrient solution (Steinkellner et al., 2005).

\section{Plant assays}

For harvesting, the plants were gently uprooted after 6 weeks. The roots were washed with running tap water. Tomato roots were submerged in autoclaved acetate buffer $(25 \mathrm{mM} ; \mathrm{pH}=5.5)$ for $6 \mathrm{~h}$ to collect root exudates. For each exudate two plants were pooled. The concentration of the exudates was adjusted according to $20 \mathrm{ml}$ buffer per one gram of root fresh weight, filtered through $0.22 \mu \mathrm{m}$ sterile filters (Thomas Scientific, USA) and stored at $-80{ }^{\circ} \mathrm{C}$. Thereafter, root and shoot fresh weights were 
determined. The disease severity and incidence was assessed both visually and by incubating a $0.5 \mathrm{~cm}$ long slice from the shoot base on potato dextrose agar media plates amended with $10 \mathrm{mg} \mathrm{L}-1$ of streptomycin (Akhter et al., 2016; Hage-Ahmed et al., $2013 \mathrm{~b}$ ). For mycorrhizal assessment, the root samples of $1 \mathrm{~cm}$ length were collected $2 \mathrm{~cm}$ below the base of shoot. To assess AMF root colonization, root samples were cleared by boiling with $10 \% \mathrm{KOH}$ and stained afterwards with a 5\% ink-vinegar solution (Vierheilig et al., 1998). The percentage of root colonization was determined according to the gridline intersect method (Newman, 1966; Giovannetti and Mosse, 1980). Roots morphological parameters (root diameter, surface area, cumulative root length and volume) were determined with the software WinRHIZO PRO (Regent Instruments QC, Canada). For this purpose, the digitized root images were obtained using an optical scanner. Specific root length depicting a ratio between root length and mass was calculated as well.

\section{In vitro effect of root exudates on $F$. oxysporum $f$. sp. lycopersici}

The 96-well plates were used to determine the $F$. oxysporum f. sp. lycopersici microconidia germination rate in the root exudates. For each treatment six root exudates were analyzed in three replicates. To each well of a plate $175 \mu 1$ of root exudates were poured along with $35 \mu \mathrm{l}$ of a conidial spore suspension $\left(1 \times 10^{7}\right.$ microconidia ml $\left.{ }^{-1}\right)$. The plates were incubated without light on a rotary shaker at $200 \mathrm{rpm}$ for $20 \mathrm{~h}$, at $24{ }^{\circ} \mathrm{C}$. Microconidia germination rate (\%) was determined microscopically after $20 \mathrm{~h}$ by observing 200 spores for the presence of germ tubes from each well.

\section{Statistical analysis}

The data analysis was performed by using PASW Statistics 18 (Version 18.0.0, IBM, Armonk, NY, USA) software. A one-way analysis of variance (ANOVA) was used to determine the treatment effects. Equality of variance was tested by the Levene's test. The percentage data was transformed before analysis. The treatment means were compared using Tukey's honestly significant difference (HSD) test, at a significance level of 5\%.

\section{Results}

\section{Plant growth assessment}

It became evident through data that tomato plant growth has been significantly increased by the intercropping partner. The details of statistical analysis have been summarized in Table 1. We documented an increase in root and shoot dry weight for tomato plants intercropped with basil (Fig. 1a, b). The tomato-basil combination has produced maximum root and shoot dry weights (1.25 and $1.97 \mathrm{~g}$, respectively) in uninoculated control treatments. In addition, the plants cope with $F$. oxysporum f. sp. lycopersici induced reduction in plant growth better, when tomato plants were intercropped with basil. Among F. oxysporum f. sp. lycopersici inoculated plants, root and shoot dry weights of the TB combinations increased by $40 \%$ and $43.80 \%$, respectively, compared to plants from the TT combinations. Co-inoculation of AMF and F. oxysporum f. sp. lycopersici showed a significant average increase of $31 \%$ in plant growth in the TB combination as compared to the TT combination. Moreover, tomato plants had produced higher shoot lengths in the TB combination with the maximum of $31 \mathrm{~cm}$ and $28.9 \mathrm{~cm}$ in un-inoculated and $F$. oxysporum f. sp. lycopersici inoculated 
treatments, respectively (Fig. 1c). However, in the TT combination shoot length was minimum in $F$. oxysporum $\mathrm{f}$. sp. lycopersici inoculated plants and plants received AMF and $F$. oxysporum $\mathrm{f}$. sp. lycopersici together $(21 \mathrm{~cm}$ and $23.5 \mathrm{~cm}$, respectively).

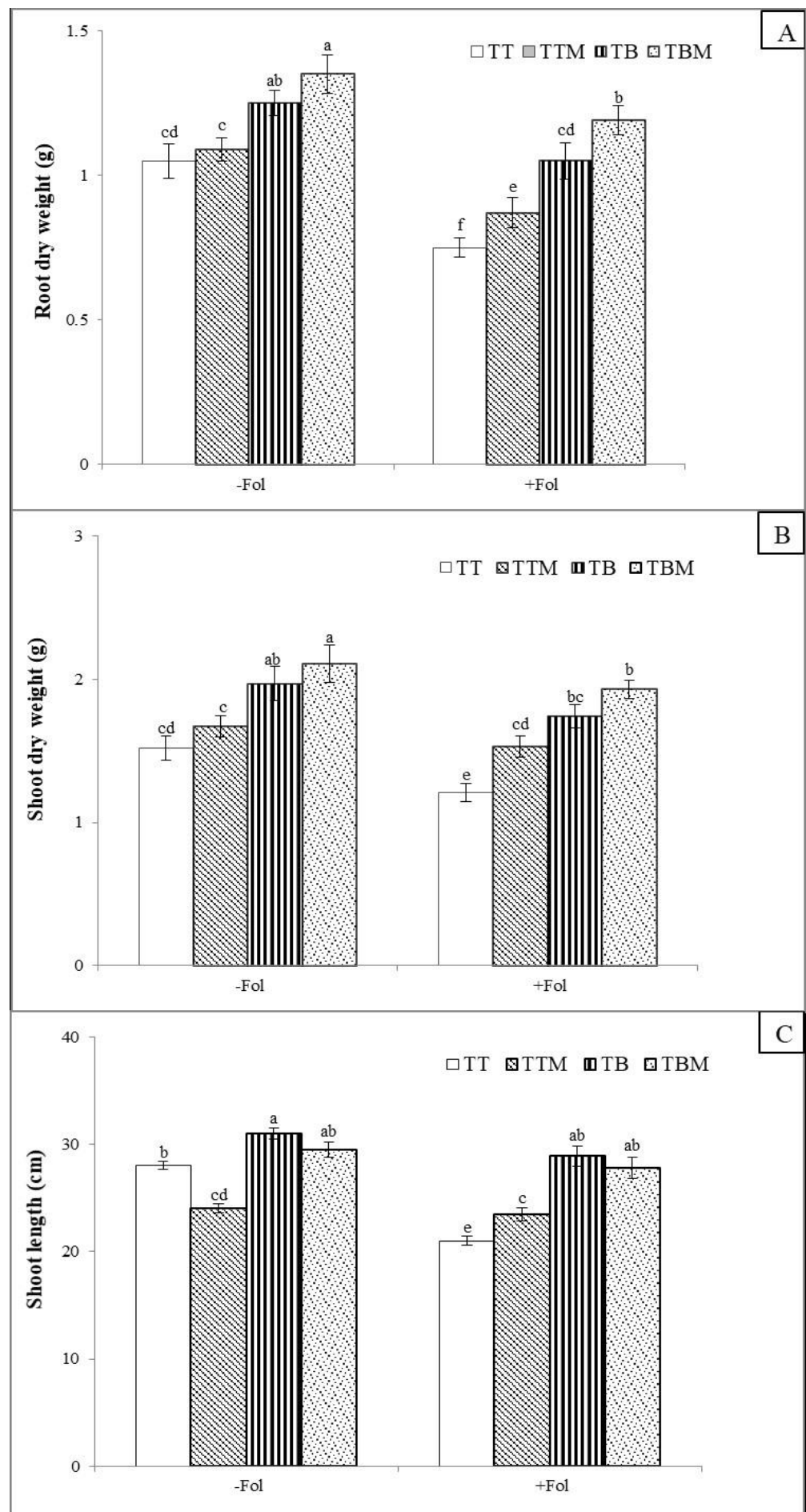

Figure 1. Effect of cropping partner and AMF on root dry weight (a), shoot dry weight (b) and shoot length (c) of tomato plants intercropped with tomato (TT) and basil (TB), either inoculated with $F$. oxysporum $f$. sp. lycopersici $(+F o l)$ or un-inoculated $(-F o l)$ and/or with the $A M F$ 'R. intraradices' $(M)($ mean \pm S.E. $)$. Bars with different letters show significant differences according to Tukey's HSD test $(P<0.05)$ 
Table 1. ANOVA results presented as degrees of freedom (DF), $F$ and $P$ values for tomato plant growth, disease severity, mycorrhizae root colonization and Fusarium oxysporum $f$. sp. lycopersici microconidia germination assay

\begin{tabular}{c|c|c|c}
\hline Parameters & DF & F & P \\
\hline Root dry weight & 7 & 12.1 & $* *$ \\
Shoot dry weight & 7 & 15.3 & $* *$ \\
Shoot height & 7 & 25.3 & $* *$ \\
Root diameter & 7 & 4.75 & $* *$ \\
Root volume & 7 & 38.1 & $* *$ \\
Root surface area & 7 & 27.1 & $* *$ \\
Root length & 7 & 37.2 & $* *$ \\
Specific root length & 7 & 2.41 & $*$ \\
Disease severity & 3 & 15.4 & $* *$ \\
Mycorrhizal root colonization & 3 & 29 & $* *$ \\
Fol microconidia germination & 4 & 135 & $* *$ \\
\hline
\end{tabular}

$* P \leq 0.05 ; * * P<0.001$

\section{Root morphology assessment}

The intercropping partner as well as AMF had no significant effect on root diameter (Fig. 2a). However, both minimum $(0.68 \mathrm{~cm})$ and maximum $(0.99 \mathrm{~cm})$ root diameter was recorded in TT combination received no inoculation and co-inoculated with AMF and $F$. oxysporum f. sp. lycopersici, respectively. Apart from root diameter, other root morphological parameters such as root volume, surface area and root length were significantly altered depending on the intercropping partner as well as on the inoculation of AMF and F. oxysporum f. sp. lycopersici (Fig. 2b, c, d; Table 1). Intercropping tomato with basil had a positive impact on the root surface area, volume and length when $F$. oxysporum f. sp. lycopersici was not present. The incorporation of AMF in the TT combination (in the absence of $F$. oxysporum $\mathrm{f}$. sp. lycopersici) resulted in the reduction of the root volume, surface area and length. On the contrary, in the TB combination with AMF the root surface area and volume remained unaltered; however, a significant reduction in root length was recorded. In the TT combination, plants inoculation with $F$. oxysporum $\mathrm{f}$. sp. lycopersici has decreased root surface area, volume and length in comparison with their un-inoculated counterparts. The inoculation with $F$. oxysporum f. sp. lycopersici in the TT combination reduced root volume and root surface area compared to the un-inoculated TT combination, in the absence of AMF. Moreover, addition of AMF had a non-significant impact on minimizing the $F$. oxysporum $\mathrm{f}$. sp. lycopersici induced reduction in above mentioned root morphological measurements in TT combination. However, the tomato plants in the TB combination co-inoculated with AMF and $F$. oxysporum $\mathrm{f}$. sp. lycopersici had sustained higher root volume $\left(0.72 \mathrm{~cm}^{3}\right)$, than plants from the TB combination without AMF (root volume; $\left.0.55 \mathrm{~cm}^{3}\right)$.

The minimum specific root length $(0.68 \mathrm{~cm} / \mathrm{mg})$ was recorded in plants of TB combination in the presence of $F$. oxysporum $\mathrm{f}$. sp. lycopersici; however, no significant differences were observed in specific root length of tomato plants grown in combination with either tomato or basil, in the absence of $F$. oxysporum f. sp. Lycopersici, both with and without AMF (Fig. 3). 


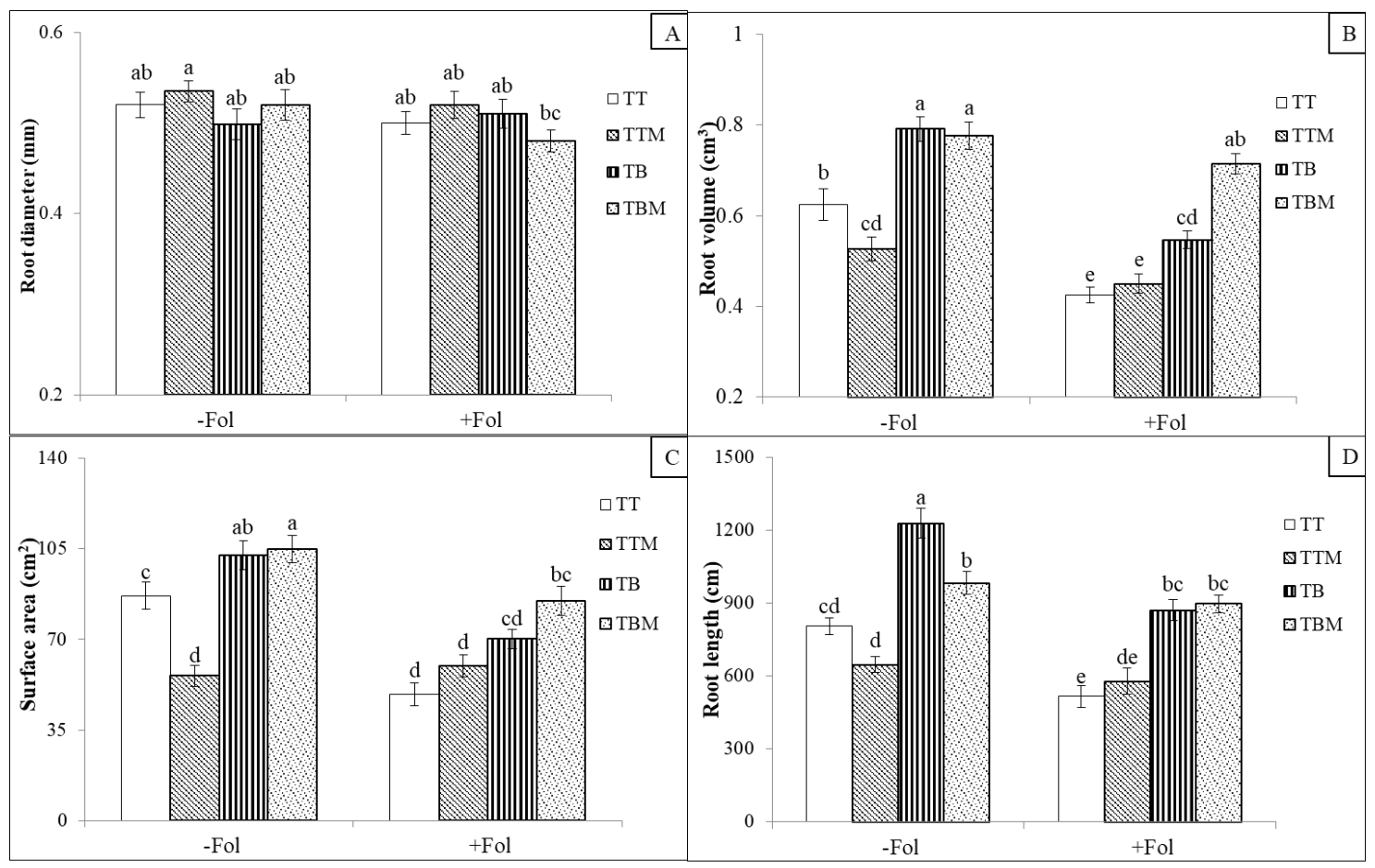

Figure 2. Effect of cropping partner and AMF on root diameter (a), volume (b), surface area (c) and root length (d) of tomato plants intercropped with tomato (TT) and basil (TB), either inoculated with $F$. oxysporum $f$. sp. lycopersici $(+F o l)$ or un-inoculated $(-F o l)$ and/or with the $A M F$ 'R. intraradices' $(M)$ (mean \pm S.E.). Bars with different letters show significant differences according to Tukey's HSD test $(P<0.05)$

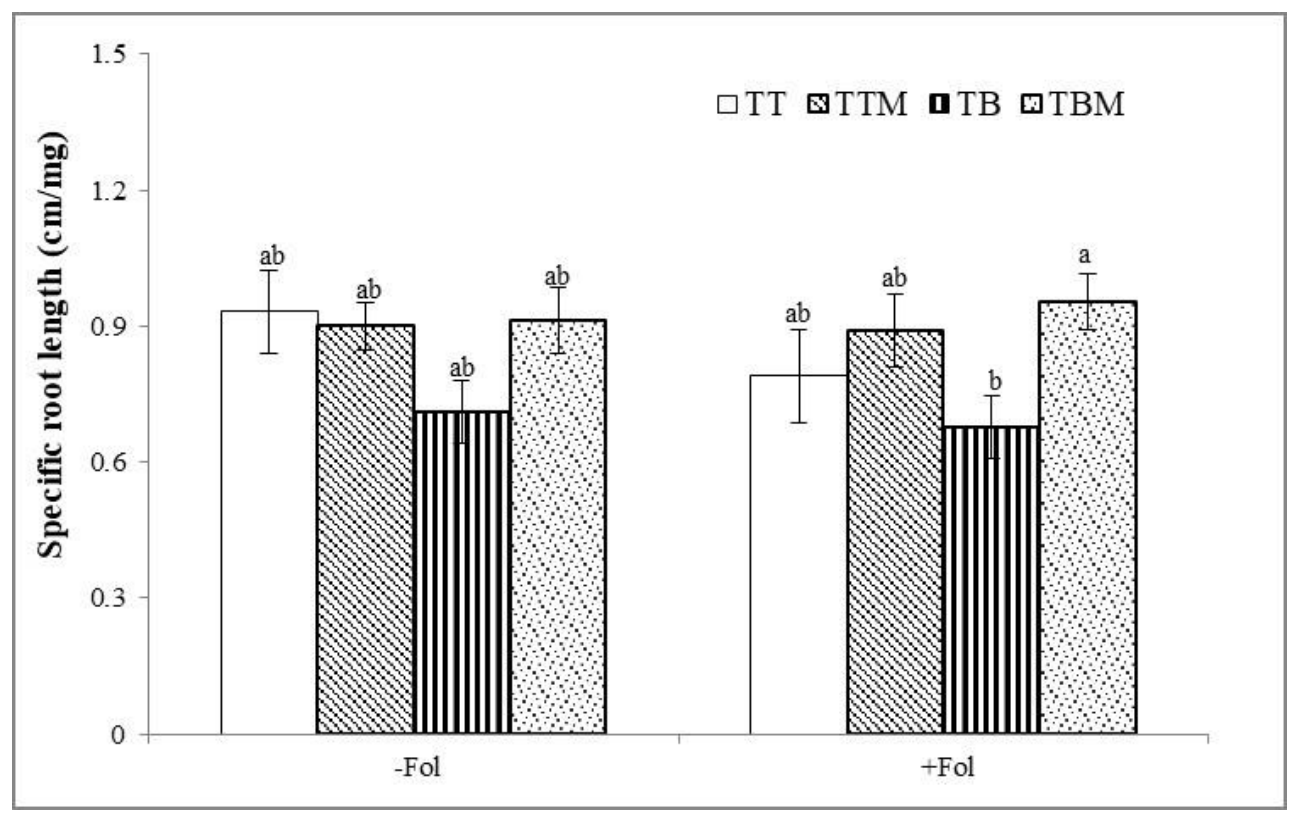

Figure 3. Effect of cropping partner and AMF on the specific root length of tomato plants intercropped with tomato (TT) and basil (TB), either inoculated with F. oxysporum $f . s p$. lycopersici $(+F o l)$ or un-inoculated $(-F o l)$ and/or with the AMF 'R. intraradices' $(M)$ (mean \pm S.E.). Bars with different letters show significant differences according to Tukey's HSD test $(P<0.05)$ 


\section{Mycorrhizal root colonization}

Six weeks after plantation, plants were harvested and root sections were stained to assess the root colonization (Fig. 4). Mycorrhizal root colonization of tomato plants was higher in TB than TT combination. Maximum root colonization (46.33 and 43.83\%) was observed in TB, where plants were inoculated with FOL and TB combination in the absence of FOL, respectively. However, F. oxysporum f. sp. lycopersici inoculated plants from TT combination has the lowest $(25.85 \%)$ rate of root colonization. Basil plants were also assessed for root colonization; an increase in basil root colonization was observed when corresponding tomato plants received co-inoculation of AMF and $F$. oxysporum $\mathrm{f}$. sp. lycopersici as compared to basil grown with $-F$ ol tomato plants (data not shown).

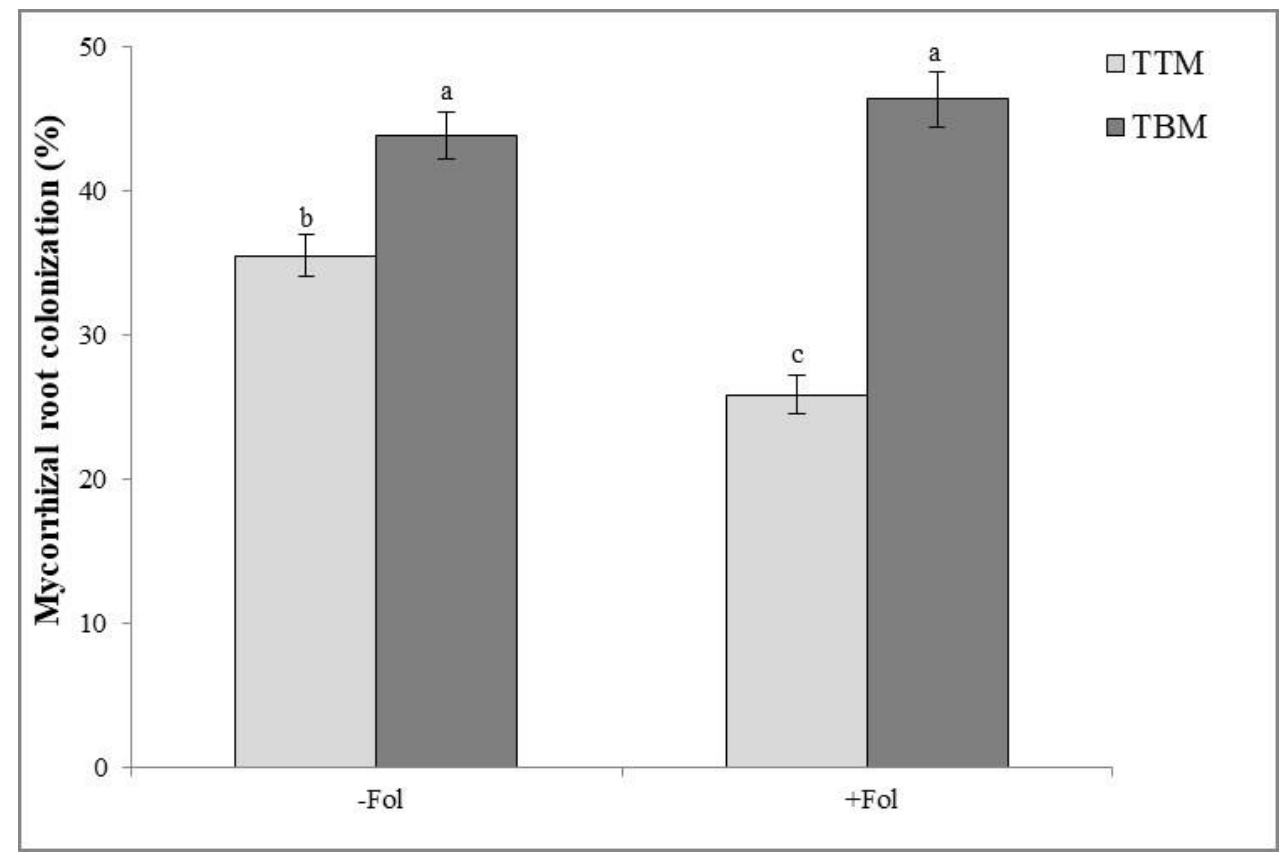

Figure 4. AMF colonization rate of tomato plants intercropped with tomato (TT) and basil $(T B)$, inoculated with F. oxysporum $f$. sp. lycopersici $(+F o l)$ or un-inoculated $(-F o l)$ (mean \pm S.E.). Bars with different letters show significant differences according to Tukey's HSD test $(P<0.05)$

\section{Disease assessment}

Table 2 summarizes the FOL disease incidence and severity on tomato plants. The pathogen $F$. oxysporum f. sp. lycopersici successfully infected the plants either grown in combination of TT or TB but the degree of infection varied depending on intercropping partner. For the plants grown in TT combination, there was maximum disease incidence and disease severity (91.67 and $32.75 \pm 8.95 \%$, respectively). However, with the incorporation of AMF, a trend in reduction $(26.82 \pm 6.46 \%)$ in disease severity was recorded in TT combination. The disease incidence of tomato plants intercropped with basil was 66.67 and $58.33 \%$ in the $F$. oxysporum f. sp. lycopersici only and coinoculated (AMF with FOL) treatments, respectively. Disease incidence in TB combination was lower than in TT combination. The co-inoculation of plants with AMF and $F$. oxysporum $\mathrm{f}$. sp. lycopersici resulted in a significant reduction in disease severity $(59.61 \%)$ as compared to the co-inoculated plants of TT combination. 
Table 2. F. oxysporum f. sp. lycopersici disease incidence and severity on tomato plants intercropped with tomato $(T T)$ and basil $(T B)$. $+A M F$ ' corresponds to the plants inoculated with R. intraradices (mean \pm S.D.)

\begin{tabular}{c|c|c|c}
\hline \multicolumn{2}{l|}{} & Disease incidence $^{\mathbf{1}}(\boldsymbol{\%})$ & Disease severity $^{\mathbf{2}}(\%)$ \\
\hline TT + Fol & -AMF & 91.67 & $32.75 \pm 8.95^{\mathrm{a}}$ \\
TB + Fol & -AMF & 66.67 & $19.21 \pm 3.57^{\mathrm{bc}}$ \\
TT + Fol & +AMF & 75 & $26.82 \pm 6.46^{\mathrm{ab}}$ \\
TB + Fol & +AMF & 58.33 & $10.83 \pm 3.28^{\mathrm{d}}$ \\
\hline
\end{tabular}

${ }^{1}$ Disease incidence was calculated for the total number of plants in each treatment

${ }^{2}$ Mean values with different letters show significant differences according to Tukey's HSD test $(P<0.05)$

\section{Microconidia germination of Fusarium oxysporum $f$. sp. lycopersici in root exudates}

The $F$. oxysporum f. sp. lycopersici microconidia germination rate in tomato root exudates and PDA broth are shown in Figure 5. Potato dextrose broth control has shown maximum $(69.65 \%)$ microconidia germination rate. The $\mathrm{pH}$ of root exudates was in the range of 5.65 to 5.83. The tomato root exudates had a variable influence on microconidia germination depending on the cropping partner and AMF. The exudates from AMF colonized plants from TT $(+\mathrm{M})$ combination showed a higher germination rate $(61.50 \%)$ in comparison to respective non-mycorrhizal counterparts [TT $(-\mathrm{M})$; $35.75 \%$ ]. However, there was a reduction of $24 \%$ in germination rate in the exudates from mycorrhizal plants in TB $(+\mathrm{M})$ combination as compared to the non-mycorrhizal $(-\mathrm{M})$ plants of the same combination. The lowest germination rate $(34.48$ and $35.75 \%)$ was recorded in TB $(+\mathrm{M})$ and $\mathrm{TB}(-\mathrm{M})$ combination, respectively.

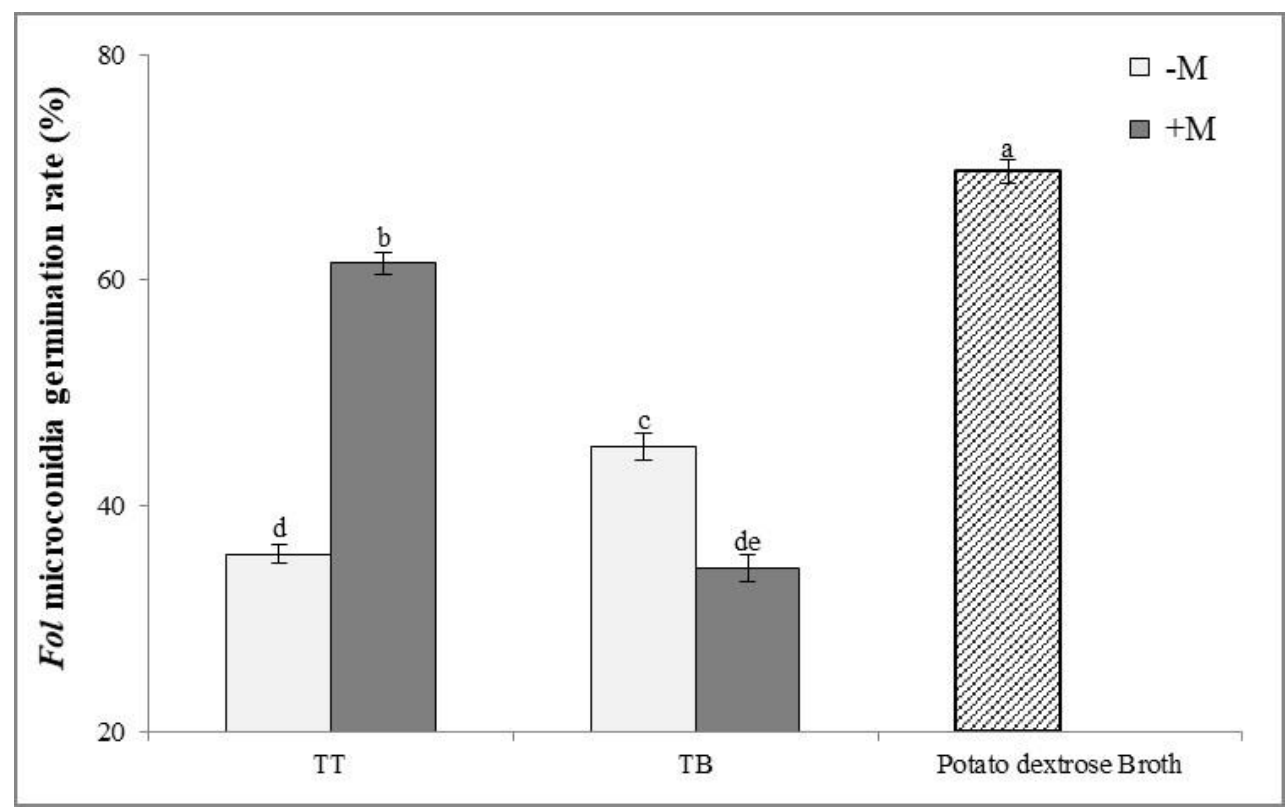

Figure 5. F. oxysporum f. sp. lycopersici (Fol) microconidia germination rate (\%) in the root exudates of tomato plants intercropped with tomato $(T T)$ and basil $(T B)$, inoculated with ' $R$.

intraradices' $(+M)$ or un-inoculated $(-M)$. Bar with pattern represents microconidia germination in Potato dextrose broth (PDA broth; control) (mean \pm S.E.). Bars with different letters show significant differences according to Tukey's HSD test $(P<0.05)$ 


\section{Discussion}

In this study a tomato-basil intercropping setting was investigated for its impact on Fusarium wilt suppression, root morphology and exudation by using a rhizobox compartment system.

Our greenhouse experiment has shown that intercropping basil with tomato significantly reduced the development of Fusarium wilt in tomatoes compared to tomato intercropped with tomato. Previous studies have documented as well the suppressive effect of interspecific plant interactions against soil borne pathogens (Yang et al., 2014; Ren et al., 2008). Earlier, Fu et al. (2015) reported that companion cropping of tomatoes with potato and onion has reduced the incidence and severity of tomato Verticillium wilt (Verticillium dahliae). The reduction of disease incidence and severity in intercropping settings could be attributed to many factors such as changes in the rhizospheric microbial communities, activation of host defense mechanisms along with allelopathic inhibition of pathogens by root exudates and other signaling compounds from the intercropping partner or by the antifungal activity of host root exudates (Fierro-Coronado et al., 2013; Gómez-Rodriguez et al., 2003; Fu et al., 2015). While, Kadoglidou et al. (2020) reported that even the soil incorporation of aromatic spearmint enhanced the tomatoes tolerance against wilt inducing FOL and Verticillium dahliae.

In contrast to the AMF - Fusarium oxysporum f. sp. basilici interaction (Toussaint et al., 2008), AMF did not confer a clear bioprotective effect against FOL. In this work, the addition of AMF did not reduce disease severity further but alleviated negative effects of Fusarium oxysporum f. sp. lycopersici on tomato root morphology. Root morphology parameters provide important information about plant physiology and nutrient uptake efficiency (Marques et al., 2016) and are therefore valuable additional indicators for the vitality status of plants challenged by soil-borne pathogens. The alterations in root morphology in response to AMF are not always comparable (Schroeder and Janos, 2005; Berta et al., 1993). AMF induced reduction in root volume, surface area and cumulative root length in the tomato-tomato combination might be due to the competition of AMF with roots for nutrients (Berta et al., 1993). In addition to that the AMF ability to take over the root function of nutrient retention from the soil can also contribute to the alterations in the root architecture (Hetrick, 1991). However, in the tomato-basil combination no greater changes in root morphology were observed in the absence of $F$. oxysporum f. sp. lycopersici. The influence of AMF on root morphological traits (root diameter, length, volume and surface area) was more prominent in $F$. oxysporum f. sp. lycopersici inoculated plants indicating disease alleviating effects. Earlier, Morauf and Steinkellner (2015) attributed any reduction in the root surface area, volume, length and weight to the $F$. oxysporum $\mathrm{f}$. sp. lycopersici inoculation in tomato plants. These alterations critically influence the ability of the plant to acquire nutrients from soil (Hodge et al., 2009). Among co-inoculated plants, tomato plants intercropped with basil had higher root length, volume and surface area as compared to their respective controls indicating greater access to nutrient reservoirs in the soil (Casper and Jackson, 1997).

Furthermore, plant biomass was increased when tomato was intercropped with basil even under disease stress as compared to tomato-tomato combination. The addition of AMF did not significantly impact on tomato plant biomass. Previous studies are contradictory concerning the influence of AMF on plant growth in intercropping settings (Hage-Ahmed et al., 2013a; Schroeder-Moreno and Janos, 2008; Lee et al., 2014). Hashem et al. (2021) reported an increase in photosynthetic and anti-oxidant 
activity of tomato plants with enhanced growth and resistance against FOL. While, Schroeder-Moreno and Janos (2008) documented the negative effect of AMF on chili, maize and zucchini plant biomass in inter- as well as intra-specific density settings, whereas, Lee et al. (2014) found that AMF inoculum consisting of a mixture of Glomus, Gigaspora, and Scutellospora sp. has significantly improved the Microstegium vimineum biomass production and $\mathrm{P}$ uptake. Van der Heijden et al. (2003) showed the dependence of the outcome of interspecific plant competition on the diversity of AMF species. Different AMF species depict contrasting ability of $\mathrm{N}$ and $\mathrm{P}$ uptake (George et al., 1995) and these differences become more prominent at genus rather than at species level (van der Heijden et al., 2003). Our results also indicate that the plant growth response was dependent on the intercropping partner but not on AMF, which contrasts with the findings of Hage-Ahmed et al. (2013a). This might be due to the fact that, in this study, we utilized a different experiment setup than Hage-Ahmed et al. (2013a) i.e. by employing a nylon membrane to avoid direct root contact of intercropping partners with each other and AMF inoculum consisting of only one species ( $R$. intraradices) instead of six different species. Thus, competition for nutrients and space for the development of roots has been minimized between intercropping partners. Therefore, allelopathic influence of basil root exudates on disease suppression and tomato plant growth promotion is likely.

Using a rhizobox compartment system also offers the possibility to study AMF colonization preferences between the different intercropping partners, indirect effects mediated by common mycorrhizal networks (CMNs) and putative influence on root exudation. Tomato intercropped with basil has shown an increase in AM root colonization in comparison to plants from the tomato-tomato $(-F$. oxysporum $\mathrm{f}$. sp. lycopersici) and tomato-tomato $(+F$. oxysporum f. sp. lycopersici) combination by $32.57 \%$ and $166.23 \%$, respectively. The plants under stress not only modify their root exudate chemistry which in turn attracts beneficial soil microflora by following a cry out for help hypothesis as proposed by Rolfe et al. (2019). Interestingly, we also found a higher rate of AM root colonization of basil (data not shown) when neighboring tomato plants were inoculated with $F$. oxysporum f. sp. lycopersici, suggesting a possible mechanism of belowground communication between plants through CMNs or root exudates. Such CMNs may contribute to the more efficient transfer of signaling and root exudate compounds from basil to tomato plants which might result into activation of induced systemic resistance against Fusarium wilt of tomato. The activation of secondary metabolic pathways in response to plant -AMF interaction contribute significantly in alleviating the effects of biotic as well as abiotic elements faced by the plants (Kaur and Suseela, 2020). Song et al. (2010) revealed that the CMNs established by AMF induced the expression of defense related genes in un-infected tomato plants neighboring Alternaria solani infected tomato plants. However, further experiments are necessary to clarify the role of CMNs in this tomato-basil intercropping setting.

In addition to CMNs, root exudates play a crucial role in determining the fate of below ground plant-microbe as well as plant-plant interactions (De-la-Pena et al., 2008; Haichar et al., 2014). Alterations in the composition of root exudates are dependent on the plant species, soil type and environment. Root exudates not only influence but also determine the outcome of tripartite plant-microbe-plant interactions (Badri and Vivanco, 2009; Xu et al., 2015). Presumably, plant species in intercropping settings depict root exudates-mediated allelopathic effects on the nearby plants and also influence the microbial communities in the rhizosphere (Ainalidou et al., 2021; Farooq 
et al., 2011). Recently, it has been shown that wheat root exudates have antifungal properties against $F$. oxysporum $\mathrm{f}$. sp. niveum in wheat-watermelon companion cropping (Xu et al., 2015), and in another study Yu (1999) reported that the tomato intercropped with Chinese chive (Allium tuberosum L.) inhibits Pseudomonas solanacearum. While, Li et al. (2021), documented the bio-protective effect of AMF against Ralstonia solanacearum in tomatoes through enhanced production of phenolic compounds and defense associated enzymes in the rhizosphere.

In this study, $F$. oxysporum $\mathrm{f}$. sp. lycopersici microconidia germination was not only influenced by the root exudates of tomato plants but also by the intercropping partner (basil). We found that there was a strong inhibition of microconidia germination in tomato (intercropped with basil) root exudates co-inoculated with $F$. oxysporum $\mathrm{f}$. sp. lycopersici and AMF; however, no such inhibition was observed in the tomato-tomato combination and in the tomato-basil combination in the absence of AMF. Hage-Ahmed et al. (2013b) associated the $F$. oxysporum $\mathrm{f}$. sp. lycopersici microconidia germination inhibition to the $F$. oxysporum $\mathrm{f}$. sp. lycopersici and AMF co-inoculation of tomato plants intercropped with cucumber. Fu et al. (2015) also documented the $V$. dahliae spore germination inhibition in tomato root exudates grown with potato onion. Our results suggest that apart from $F$. oxysporum f. sp. lycopersici and AMF, the intercropping partner also significantly contributes to the plant response and the pathogen behavior in the root exudates.

\section{Conclusion}

In conclusion, intercropping basil with tomato successfully alleviates Fusarium wilt stress even without direct root contact. The addition of AMF increases the tolerance of the host plant towards Fusarium wilt further by affecting tomato root morphology and exudate dynamics. Thus, the combination of intercropping and AMF application represent an additional tool in sustainable agricultural management practices to reduce the soil-borne pathogen $F$. oxysporum $\mathrm{f}$. sp. lycopersici. Further studies are required to analyze the variations in the tomato root exudate chemistry in response to different intercropping partners and to determine the consequence of interaction between plant (tomato)-plant (basil)-AMF and F. oxysporum f. sp. lycopersici and other rhizosphere inhabitants.

Acknowledgements. The authors would like to extend their sincere appreciation to the Researchers Supporting Project Number (RSP-2021/134), King Saud University, Riyadh, Saudi Arabia.

\section{REFERENCES}

[1] Ainalidou, A., Bouzoukla, F., Menkissoglu-Spiroudi, U., Vokou, D., Karamanoli, K. (2021): Impacts of decaying aromatic plants on the soil microbial community and on tomato seedling growth and metabolism: suppression or stimulation? - Plants 10(9): 1848 .

[2] Akhter, A., Hage-Ahmed, K., Soja, G., Steinkellner, S. (2016): Potential of Fusarium wilt-inducing chlamydospores, in vitro behaviour in root exudates and physiology of tomato in biochar and compost amended soil. - Plant and Soil 406: 425-440.

[3] Badri, D. V., Vivanco, J. M. (2009): Regulation and function of root exudates. - Plant, Cell and Environment 32: 666-681. 
[4] Berta, G., Fusconi, A., Trotta, A. (1993): VA mycorrhizal infection and the morphology and function of root systems. - Environmental and Experimental Botany 33: 159-173.

[5] Bomford, M. K. (2009): Do tomatoes love basil but hate Brussels sprouts? Competition and land-use efficiency of popularly recommended and discouraged crop mixtures in biointensive agriculture systems. - Journal of Sustainable Agriculture 33: 396-417.

[6] Brundrett, M. C. (2002): Coevolution of roots and mycorrhizas of land plants. - New Phytologist 154: 275-304.

[7] Casper, B. B., Jackson, R. B. (1997): Plant competition underground. - Annual Review of Ecology, Evolution and Systematics 28: 545-570.

[8] Dehne, H. W., Schönbeck, F. (1979): Influence of endotrophic mycorrhiza on plant diseases. II. Phenol metabolism and lignification. - Journal of Phytopathology 95: 210216.

[9] De-la-Pena, C., Lei, Z., Watson, B. S., Sumner, L. W., Vivanco, J. M. (2008): Rootmicrobe communication through protein secretion. - Journal of Biological Chemistry 283: 25247-25255.

[10] Farooq, M., Jabran, K., Cheema, Z. A., Wahid, A., Siddique, K. H. (2011): The role of allelopathy in agricultural pest management. - Pest Management Science 67: 493-506.

[11] Fierro-Coronado, R. A., Castro-Moreno, M. G., Ruelas-Ayala, R. D., Apodaca-Sánchez, M. Á., Maldonado-Mendoza, I. E. (2013): Induced protection by Rhizophagus intraradices against Fusarium wilt of tomato. - Interciencia 38: 48-53.

[12] Fu, X., Wu, X., Zhou, X., Liu, S., Shen, Y., Wu, F. (2015): Companion cropping with potato onion enhances the disease resistance of tomato against Verticillium dahliae. Frontiers in Plant Science 6: 726.

[13] George, E., Marschner, H., Jakobsen, I. (1995): Role of arbuscular mycorrhizal fungi in uptake of phosphorus and nitrogen from soil. - Critical Reviews in Biotechnology 15: 257-270.

[14] Giovannetti, M., Mosse, B. (1980): An evaluation of techniques for measuring vesicular arbuscular mycorrhizal infection in roots. - New Phytologist 84: 489-500.

[15] Gómez-Rodriguez, O., Zavaleta-Mejıa, E., Gonzalez-Hernandez, V. A., Livera-Munoz, M., Cárdenas-Soriano, E. (2003): Allelopathy and microclimatic modification of intercropping with marigold on tomato early blight disease development. - Field Crop Research 83: 27-34.

[16] Hage-Ahmed, K., Krammer, J., Steinkellner, S. (2013a). The intercropping partner affects arbuscular mycorrhizal fungi and Fusarium oxysporum f. sp. lycopersici interactions in tomato. - Mycorrhiza 23: 543-550.

[17] Hage-Ahmed, K., Moyses, A., Voglgruber, A., Hadacek, F., Steinkellner, S. (2013b): Alterations in root exudation of inter-cropped tomato mediated by the arbuscular mycorrhizal fungus Glomus mosseae and the soil borne pathogen Fusarium oxysporum $\mathrm{f}$. sp. lycopersici. - Journal of Phytopathology 161: 763-773.

[18] Haichar, F. Z., Santaella, C., Heulin, T., Achouak, W. (2014): Root exudates mediated interactions belowground. - Soil Biology and Biochemistry 77: 69-80.

[19] Hashem, A., Akhter, A., Alqarawi, A. A., Singh, G., Almutairi, K. F., Abd_Allah, E. F. (2021): Mycorrhizal fungi induced activation of tomato defense system mitigates Fusarium wilt stress. - Saudi Journal of Biological Sciences 1-9.

[20] Hetrick, B. A. D. (1991): Mycorrhizas and root architecture. - Cellular and Molecular Life Sciences 47: 355-362.

[21] Hodge, A., Berta, G., Doussan, C., Merchan, F., Crespi, M. (2009): Plant root growth, architecture and function. - Plant and Soil. 321: 153-187.

[22] Kadoglidou, K., Chatzopoulou, P., Maloupa, E., Kalaitzidis, A., Ghoghoberidze, S., Katsantonis, D. (2020): Mentha and oregano soil amendment induces enhancement of tomato tolerance against soilborne diseases, yield and quality. - Agronomy 10(3): 406.

[23] Kaur, S., Suseela, V. (2020): Unraveling arbuscular mycorrhiza-induced changes in plant primary and secondary metabolome. - Metabolites 10(8) 335. 
[24] Kong, C., Liang, W., Xu, X., Hu, F., Wang, P., Jiang, Y. (2004): Release and activity of allelochemicals from allelopathic rice seedlings. - Journal of Agricultural and Food Chemistry 52: 2861-2865.

[25] Lee, M. R., Tu, C., Chen, X., Hu, S. (2014): Arbuscular mycorrhizal fungi enhance P uptake and alter plant morphology in the invasive plant Microstegium vimineum. Biological Invasions 16: 1083-1093.

[26] Li, M., Hou, S., Wang, J., Hu, J., Lin, X. (2021): Arbuscular mycorrhizal fungus suppresses tomato (Solanum lycopersicum Mill.) Ralstonia wilt via establishing a soilplant integrated defense system. - Journal of Soils and Sediments 1-13.

[27] Marques, D. J., da Silva, E. C., Ferreira, M. M., Paglis, C. M., de Souza, T. C., Maluf, W. R. (2016): Differential responses of root system and gas exchange in contrasting tomato genotypes under phosphorus starvation. - Australian Journal of Crop Science 10: 101110.

[28] Morauf, C., Steinkellner, S. (2015): Fusarium oxysporum f. sp. lycopersici and compost affect tomato root morphology. - European Journal of Plant Pathology 143: 385-398.

[29] Newman, E. I. (1966): A method of estimating the total length of root in a sample. Journal of Applied Ecology 3: 139-145.

[30] Ramyabharathi, S. A., Meena, B., Raguchander, T. (2012): Induction of chitinase and $\beta-$ 1,3- glucanase PR proteins in tomato through liquid formulated Bacillus subtilis EPCO 16 against Fusarium wilt. - Journal of Today's Biological Sciences 1: 50-60.

[31] Ren, L., Su, S., Yang, X., Xu, Y., Huang, Q., Shen, Q. (2008): Intercropping with aerobic rice suppressed Fusarium wilt in watermelon. - Soil Biology and Biochemistry 40: 834844.

[32] Rice, E. L. (1984): Allelopathy. Second Ed. - Academic Press, Orlando.

[33] Riotte, L. (1975): Carrots Love Tomatoes: Secrets of Companion Planting for Successful Gardening. - Storey Books, Pownal.

[34] Rolfe, S. A., Griffiths, J., Ton, J. (2019): Crying out for help with root exudates: adaptive mechanisms by which stressed plants assemble health-promoting soil microbiomes. Current Opinion in Microbiology 49: 73-82.

[35] Salehi, Y., Zarehaghi, D., Dabbagh Mohammadi Nasab, A., Neyshabouri, M. R. (2018): The Effect of intercropping and deficit irrigation on the water use efficiency and yield of tomato (Lycopersicon esculentum mill) and Basil (Ocimum basilicum). - Journal of Agricultural Science and Sustainable Production 28(3): 209-220.

[36] Scheffknecht, S., Mammerler, R., Steinkellner, S., Vierheilig, H. (2006): Root exudates of mycorrhizal tomato plants exhibit a different effect on microconidia germination of Fusarium oxysporum f. sp. lycopersici than root exudates from non-mycorrhizal tomato plants. - Mycorrhiza 16: 365-370.

[37] Schroeder, M. S., Janos, D. P. (2005): Plant growth, phosphorus nutrition, and root morphological responses to arbuscular mycorrhizas, phosphorus fertilization, and intraspecific density. - Mycorrhiza 15: 203-216.

[38] Schroeder-Moreno, M. S., Janos, D. P. (2008): Intra- and inter-specific density affects plant growth responses to arbuscular mycorrhizas. - Botany. 86: 1180-1193.

[39] Smith, S. E., Read, D. J. (2008): Mycorrhizal Symbiosis. Third Ed. - Academic Press, London.

[40] Son, D., Somda, I., Legreve, A., Schiffers, B. (2018): Effect of plant diversification on pest abundance and tomato yields in two cropping systems in Burkina Faso: farmer practices and integrated pest management. - International Journal of Biological and Chemical Sciences 12(1): 101-119.

[41] Song, Y. Y., Zeng, R. S., Xu, J. F., Li, J., Shen, X., Yihdego, W. G. (2010): Interplant communication of tomato plants through underground common mycorrhizal networks. PLOS ONE 5: 13324. 
[42] Steinkellner, S., Mammarler, R., Vierheilig, H. (2005): Microconidia germination of tomato pathogen Fusarium oxysporum in the presence of root exudates. - Journal of Plant Interactions 1: 23-30.

[43] Toussaint, J. P., Kraml, M., Nell, M., Smith, S. E., Smith, F. A., Steinkellner, S., Schmiderer, C., Vierheilig, H., Novak, J. (2008): Effect of Glomus mosseae on concentrations of rosmarinic and caffeic acids and essential oil compounds in basil inoculated with Fusarium oxysporum f. sp. basilici. - Plant Pathology 57: 1109-1116.

[44] Van der Heijden, M., Wiemken, A., Sanders, I. (2003): Different arbuscular mycorrhizal fungi alter coexistence and resource distribution between co-occuring plant. - New Phytologist 157: 569-578.

[45] Vierheilig, H., Coughlan, A. P., Wyss, U., Piché, Y. (1998): Ink and vinegar, a simple staining technique for arbuscular-mycorrhizal fungi. - Applied and Environmental Microbiology 64: 5004-5007.

[46] Vierheilig, H., Garcia-Garrido, J. M., Wyss, U., Piché, Y. (2000): Systemic suppression of mycorrhizal colonization on barley roots already colonized by AM fungi. - Soil Biology and Biochemistry 32: 589-595.

[47] Xu, W., Liu, D., Wu, F., Liu, S. (2015): Root exudates of wheat are involved in suppression of Fusarium wilt in watermelon in watermelon-wheat companion cropping. European Journal of Plant Pathology 141: 209-216.

[48] Yang, M., Zhang, Y., Qi, L., Mei, X., Liao, J., Ding, X. (2014): Plant-plant-microbe mechanisms involved in soil-borne disease suppression on a maize and pepper intercropping system. - PLoS ONE 9: e115052.

[49] Yu, J. Q. (1999): Allelopathic suppression of Pseudomonas solanacearum infection of tomato (Lycopersicon esculentum) in a tomato- Chinese chive (Allium tuberosum) intercropping system. - Journal of Chemical Ecology 25: 2409-2417. 